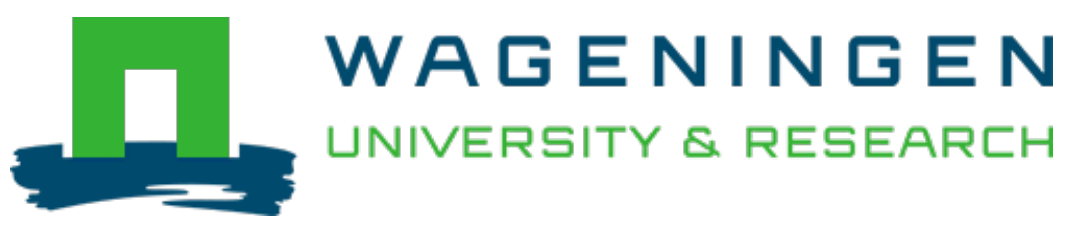

\author{
Effect of sublethal preculturing on the survival of probiotics and metabolite \\ formation in set-yoghurt \\ Food Microbiology \\ Settachaimongkon, S.; Valenberg, H.J.F.; Winata, V.; Wang, X.; Nout, M.J.R. et al \\ https://doi.org/10.1016/j.fm.2015.01.011
}

This publication is made publicly available in the institutional repository of Wageningen University and Research, under the terms of article $25 \mathrm{fa}$ of the Dutch Copyright Act, also known as the Amendment Taverne. This has been done with explicit consent by the author.

Article 25 fa states that the author of a short scientific work funded either wholly or partially by Dutch public funds is entitled to make that work publicly available for no consideration following a reasonable period of time after the work was first published, provided that clear reference is made to the source of the first publication of the work.

This publication is distributed under The Association of Universities in the Netherlands (VSNU) 'Article $25 \mathrm{fa}$ implementation' project. In this project research outputs of researchers employed by Dutch Universities that comply with the legal requirements of Article $25 \mathrm{fa}$ of the Dutch Copyright Act are distributed online and free of cost or other barriers in institutional repositories. Research outputs are distributed six months after their first online publication in the original published version and with proper attribution to the source of the original publication.

You are permitted to download and use the publication for personal purposes. All rights remain with the author(s) and / or copyright owner(s) of this work. Any use of the publication or parts of it other than authorised under article $25 \mathrm{fa}$ of the Dutch Copyright act is prohibited. Wageningen University \& Research and the author(s) of this publication shall not be held responsible or liable for any damages resulting from your (re)use of this publication.

For questions regarding the public availability of this publication please contact openscience.library@wur.nl 


\title{
Effect of sublethal preculturing on the survival of probiotics and metabolite formation in set-yoghurt
}

\author{
Sarn Settachaimongkon ${ }^{\text {a }}$, Hein J.F. van Valenberg ${ }^{\mathrm{b}}$, Vera Winata ${ }^{\mathrm{b}}$, Xiaoxi Wang ${ }^{\mathrm{b}}$, \\ M.J. Robert Nout ${ }^{c}$, Toon C.M. van Hooijdonk ${ }^{b}$, Marcel H. Zwietering ${ }^{c}$, Eddy J. Smid ${ }^{\text {c, * }}$ \\ a Department of Food Technology, Faculty of Science, Chulalongkorn University, Bangkok, 10330, Thailand \\ b Dairy Science and Technology Group, Chair of Food Quality and Design, Wageningen University, P.O. Box 17, 6700 AA, Wageningen, The Netherlands \\ ${ }^{\mathrm{c}}$ Laboratory of Food Microbiology, Wageningen University, P.O. Box 17, 6700 AA, Wageningen, The Netherlands
}

\section{A R T I C L E I N F O}

\section{Article history:}

Received 10 March 2014

Received in revised form

23 January 2015

Accepted 31 January 2015

Available online 17 February 2015

\section{Keywords:}

Dairy

Fermented milk

Lactic acid bacteria

Stress adaptation

Flavor

Metabolomics

\begin{abstract}
A B S T R A C T
The objective of this study was to investigate the effect of preculturing of Lactobacillus rhamnosus GG and Bifidobacterium animalis subsp. lactis BB12 under sublethal stress conditions on their survival and metabolite formation in set-yoghurt. Prior to co-cultivation with yoghurt starters in milk, the two probiotic strains were precultured under sublethal stress conditions (combinations of elevated $\mathrm{NaCl}$ and low $\mathrm{pH})$ in a batch fermentor. The activity of sublethally precultured probiotics was evaluated during fermentation and refrigerated storage by monitoring bacterial population dynamics, milk acidification and changes in volatile and non-volatile metabolite profiles of set-yoghurt. The results demonstrated adaptive stress responses of the two probiotic strains resulting in their viability improvement without adverse influence on milk acidification. A complementary metabolomic approach using SPME-GC/MS and ${ }^{1} \mathrm{H}-\mathrm{NMR}$ resulted in the identification of 35 volatiles and 43 non-volatile polar metabolites, respectively. Principal component analysis revealed substantial impact of the activity of sublethally precultured probiotics on metabolite formation demonstrated by distinctive volatile and non-volatile metabolite profiles of set-yoghurt. Changes in relative abundance of various aroma compounds suggest that incorporation of stress-adapted probiotics considerably influences the organoleptic quality of product. This study provides new information on the application of stress-adapted probiotics in an actual food-carrier environment.
\end{abstract}

() 2015 Elsevier Ltd. All rights reserved.

\section{Introduction}

During the past decades, societal interest in healthy foods has contributed to the development of functional dairy products that potentially provide health benefits in addition to the fundamental nutrients they contain (Shiby and Mishra, 2013). An example of a functional type of yoghurt is one that carries "probiotics" which are defined as live microorganisms which when administered in adequate amounts confer a health benefit on the host (FAO/WHO, 2002). This definition underlines that probiotics need to be alive and present in sufficiently high number at the time of consumption to ensure their health-promoting effects. With respect to this, a probiotic product should contain at least $10^{6} \mathrm{CFU} / \mathrm{g}$ of viable probiotic cells throughout the entire shelf-life (Vasiljevic and Shah,

\footnotetext{
* Corresponding author. Tel.: +31 317 484978; fax: +31 317482834 .

E-mail address: eddy.smid@wur.nl (E.J. Smid).
}

2008). Most commercial probiotics incorporated in dairy products are strains belonging to the genera Lactobacillus and Bifidobacterium (Lourens-Hattingh and Viljoen, 2001). However, many of these strains exhibit a low capacity to grow in milk during fermentation and are not able to survive well in fermented milk during refrigerated storage (Gueimonde et al., 2004), mainly due to the reduction of pH and accumulation of organic acids (Shah, 2000).

Stress adaptation is one of the strategies to improve the survival of probiotics. This is achieved by pre-treating (preculturing) them in a sublethal stress condition prior to exposure to a more harsh or lethal environment (Upadrasta et al., 2011). This approach allows probiotic bacteria to develop adaptive stress responses leading to an increase in their survival compared to those that are directly shifted into the same lethal stress condition (Saarela et al., 2004). Adaptive responses towards various types of stress, i.e. heat, cold, acid, bile salts, osmotic, oxygen, high pressure and nutrient starvation, have been well documented for lactobacilli and bifidobacteria (De Angelis and Gobbetti, 2004; Ruiz et al., 2011; Tsakalidou 
and Papadimitriou, 2011; Van de Guchte et al., 2002). These stress features usually resemble the environmental niches typically encountered by probiotics during human gastrointestinal tract transit, during industrial-scale production and in the food matrix (Ruiz et al., 2011). Acid and osmotic stress, as consequences of lactic acid production and application of food additives, are the most predominant stress factors during yoghurt manufacture and refrigerated storage (Mohammadi et al., 2012). Recent advances in post-genomics technologies, i.e. transcriptomics and proteomics, have provided novel insights into how probiotics counteract environmental stresses (Sánchez et al., 2013). Despite high numbers of publications focusing on the molecular basis of stress responses in probiotics, there is only a limited number of studies investigating the fate of stress-adapted bacteria when administered in a real food system such as milk and yoghurt (Giraffa, 2012; Maus and Ingham, 2003; Mills et al., 2011; Shah, 2000). Particularly, the influence of metabolic activity of stress-adapted probiotics on the biochemical characteristics of the food-carrier received little attention.

Metabolomics is recognized as an effective tool to investigate the overall chemical composition of complex biological systems including food matrices (Herrero et al., 2012). The application of mass spectrometry (MS) and nuclear magnetic resonance (NMR) has shown to be successful in determining a wide range of metabolites in fermented dairy products (Mozzi et al., 2013; Piras et al., 2013; Rodrigues et al., 2011; Settachaimongkon et al., 2014a). This approach can be implemented for monitoring the overall biochemical changes associated with the metabolic activity of starter cultures and probiotics during yoghurt manufacture (Mozzi et al., 2013; Sánchez et al., 2013; Settachaimongkon et al., 2014b). The outcomes are expected to provide new information concerning the impact of stress-adapted probiotics applied in yoghurt, since their metabolic responses may substantially affect the biochemical and organoleptic characteristics of this product (Serrazanetti et al., 2009).

The objective of this study was to investigate the impact of preculturing of two commercial probiotic strains, Lactobacillus rhamnosus GG and Bifidobacterium animalis subsp. lactis BB12, under sublethal stress conditions (combinations of elevated $\mathrm{NaCl}$ and adjusted $\mathrm{pH}$ ) on their survival and metabolite formation in setyoghurt. Changes in viable counts of yoghurt starters as well as probiotics and extent of milk acidification were monitored during fermentation and refrigerated storage. Furthermore, biochemical changes associated with bacterial metabolism were characterized by a metabolomics approach using headspace SPME-GC/MS and ${ }^{1} \mathrm{H}$-NMR technique. Finally, multivariate analysis was applied to analyze volatile and non-volatile polar metabolite profiles of setyoghurts.

\section{Materials and methods}

\subsection{Yoghurt starters and probiotic strains}

Frozen direct-vat-inoculation pellets of Streptococcus thermophilus C44, Lactobacillus delbrueckii subsp. bulgaricus C49 (CSK Food Enrichment, Ede, the Netherlands) and B. animalis subsp. lactis BB12 (BB12) (Chr. Hansen, Hørsholm, Denmark) were stored at $-45{ }^{\circ} \mathrm{C}$. A culture of $L$. rhamnosus GG (LGG) (ATCC 53103) was propagated in our laboratory and stored as a $20 \%(\mathrm{v} / \mathrm{v})$ glycerol stock-culture at $-80{ }^{\circ} \mathrm{C}$. Frozen cultures were transferred to ambient temperature $\left(20 \pm 3{ }^{\circ} \mathrm{C}\right)$ for $15 \mathrm{~min}$ before use. Probiotic strains were refreshed in MRS broth $(1 \%(\mathrm{v} / \mathrm{v})$ inoculation $)(0.5 \mathrm{~g} / \mathrm{L}$ cysteine- $\mathrm{HCl}$ supplemented for BB12) (Merck, Darmstadt, Germany) at $37^{\circ} \mathrm{C}$ for $24 \mathrm{~h}$ under anaerobic incubation (Anoxomat ${ }^{\mathrm{TM}}$ Mart $^{\circledR}$, Drachten, the Netherlands). Then, the cells were collected by centrifugation at $4000 \times \mathrm{g}$ for $15 \mathrm{~min}$ at $4{ }^{\circ} \mathrm{C}$, washed twice using peptone-physiological-salt solution (Tritium microbiology, Eindhoven, the Netherlands) and finally resuspended in milk to obtain the cell density at approximately $10^{8} \mathrm{CFU} / \mathrm{g}$ before inoculation. These cultures were defined as control groups, i.e. standard precultured LGG and BB12.

\subsection{Preculturing of probiotics under sublethal stress conditions}

\subsubsection{Screening for sublethal stress conditions}

Suitable sublethal stress conditions, combinations of elevated $\mathrm{NaCl}$ concentrations and low $\mathrm{pH}$ values, for LGG and BB12 were preliminary determined. For screening of sublethal salt levels, probiotic cells were cultured in $\mathrm{NaCl}$-adjusted MRS broth $(0.5 \mathrm{~g} / \mathrm{L}$ cysteine- $\mathrm{HCl}$ supplemented for BB12). $\mathrm{NaCl}$ (Merck, Darmstadt, Germany) was added to MRS broth at concentrations ranging from $0.5 \%$ to $5.0 \%(\mathrm{w} / \mathrm{v})$ with a $0.5 \%$ interval level. The concentrations which caused 0.5 and $1.0 \mathrm{log}$ reduction of viable probiotic cells compared to those enumerated in unsalted MRS broth after anaerobic incubation at $37{ }^{\circ} \mathrm{C}$ for $24 \mathrm{~h}$ (data not shown) were considered as low and high sublethal $\mathrm{NaCl}$ levels, i.e. 2.0\%/4.0\% (w/ v) for LGG and $0.5 \% / 1.5 \%(\mathrm{w} / \mathrm{v})$ for BB12. Sublethal $\mathrm{pH}$ values for LGG and BB12 were assigned at $1.0 \mathrm{pH}$ unit above and below the optimum pH for their growth, i.e. pH 4.5/6.5 (LGG) and pH 5.0/7.0 (BB12). The combinations of sublethal NaCl-pH treatments were finally organized as a $2 \times 2$ between subjects factorial design (Table 1).

\subsubsection{Preculturing of probiotics in a batch fermentor}

Preculturing of probiotics was conducted in a $750 \mathrm{~mL}$ Multifors2 Bacterial System Bioreactor fully operated by IRIS-V.5.3 control software (Infors HT, Bottmingen, Switzerland). The fermentor was filled with $350 \mathrm{~mL} \mathrm{NaCl}$-adjusted MRS broth and then was equipped with auxiliary devices (tubes, gas-pipes, pumps, reagent bottles, sampling system, $\mathrm{pH}$, optical density and temperature sensors) before sterilization $\left(121^{\circ} \mathrm{C}\right.$ for $\left.30 \mathrm{~min}\right)$. For BB12, the medium was supplemented with $0.5 \mathrm{~g} / \mathrm{L}$ cysteine- $\mathrm{HCl}$ after sterilization. The $\mathrm{pH}$ of the medium was adjusted and automatically maintained at a desired pre-set value (pH-stat) by adding $1 \mathrm{~N} \mathrm{NaOH}$ or $1 \mathrm{~N} \mathrm{HCl}$. A fresh overnight culture of the probiotics was inoculated at $1 \%(\mathrm{v} / \mathrm{v})$ into the $\mathrm{NaCl}-\mathrm{pH}$ adjusted medium. Batch scale preculturing was carried out at $37^{\circ} \mathrm{C}$ for $24 \mathrm{~h}$ under anaerobic condition created by a continuous $\mathrm{N}_{2}$-flushing system with a flow rate of $1 \mathrm{~L} / \mathrm{min}$ through a $0.22 \mu \mathrm{m}$ filter. The medium was continuously stirred at a constant speed of $100 \mathrm{rpm}$. After $24 \mathrm{~h}$ (stationary phase monitored by optical density; data not shown), sublethally precultured probiotic cells were collected by centrifugation at $4000 \times \mathrm{g}$ for $15 \mathrm{~min}$ at $4{ }^{\circ} \mathrm{C}$, washed twice using peptone-physiological-salt solution and the cell pellets were finally resuspended in milk before use. These steps were performed to avoid carryover effect of nutrients from MRS broth which is a nonfood-grade laboratory medium (Saarela et al., 2004). Sublethally precultured probiotics were subsequently inoculated in co-cultures with traditional yoghurt starters as described previously (Settachaimongkon et al., 2014b). The

\section{Table 1}

Sublethal stress conditions (combinations of elevated salt and low $\mathrm{pH}$ ) in modified MRS broth for preculturing of $L$. rhamnosus GG (LGG) and B. animalis subsp. lactis BB12 (BB12) in a batch fermentor.

\begin{tabular}{llll}
\hline Probiotics & Salt stress & Acid stress \\
\cline { 3 - 4 } & & Low pH & Neutral pH \\
\hline \multirow{2}{*}{ LGG } & Low \%NaCl & $2.0 \% \mathrm{NaCl}-\mathrm{pH} 4.5$ & $2.0 \% \mathrm{NaCl}-\mathrm{pH} 6.5$ \\
& High \% $\mathrm{NaCl}$ & $4.0 \% \mathrm{NaCl}-\mathrm{pH} 4.5$ & $4.0 \% \mathrm{NaCl}-\mathrm{pH} 6.5$ \\
BB12 & Low \%NaCl & $0.5 \% \mathrm{NaCl}-\mathrm{pH} 5.0$ & $0.5 \% \mathrm{NaCl}-\mathrm{pH} 7.0$ \\
& High \%NaCl & $1.5 \% \mathrm{NaCl}-\mathrm{pH} 5.0$ & $1.5 \% \mathrm{NaCl}-\mathrm{pH} 7.0$ \\
\hline
\end{tabular}


preculturing was performed in three batches for each stress combination.

\subsection{Set-yoghurt fermentation}

Reconstituted Nilac skimmed milk (NIZO Food Research, Ede, the Netherlands) was prepared according to the method previously described (Settachaimongkon et al., 2014a). Set-yoghurts were fermented with two types of starter combinations: (i) co-cultures of yoghurt starters with LGG and (ii) co-cultures of yoghurt starters with BB12. The initial inoculum size of the two yoghurt starters and probiotic strains were adjusted respectively at $10^{6} \mathrm{CFU} / \mathrm{g}$ (ratio $1: 1: 1)$. After inoculation, set-yoghurt fermentation and sample collection were carried out according to the methods previously described (Settachaimongkon et al., 2014b). The fermentation was performed in three replicates for each type of starter combination.

\subsection{Enumeration of viable bacteria}

Viable counts of $S$. thermophilus, L. delbrueckii subsp. bulgaricus, L. rhamnosus GG and B. animalis subsp. lactis BB12 were determined according to the methods described previously (Settachaimongkon et al., 2014b).

\subsection{Determination of acidification profile}

Production of acid during set-yoghurt fermentation and storage was expressed by changes in $\mathrm{pH}$ and increases in titratable acidity as described previously (Settachaimongkon et al., 2014a).

\subsection{Analysis of volatile metabolites by headspace SPME-GC/MS}

A model scenario of set-yoghurt fermentation was carried out directly in GC vials (Settachaimongkon et al., 2014a). The fermentation was performed in three replicates for each type of starter combination. Extraction and determination of volatile compounds by headspace SPME-GC/MS were performed according to the method previously described (Settachaimongkon et al., 2014a). Volatile metabolites were identified using AMDIS software (NIST, Gaithersburg, MD, USA) referred to NIST/EPA/NIH database and the library provided by Hettinga et al. (2009). Specific retention time and $\mathrm{m} / \mathrm{z}$ model were used for automated peak integration in XCalibur software package (Thermo Scientific, Austin, TX, USA).

\subsection{Analysis of non-volatile polar metabolites by ${ }^{1} \mathrm{H}-\mathrm{NMR}$ spectroscopy}

For ${ }^{1} \mathrm{H}-\mathrm{NMR}$ analysis, the samples from two replicates were prepared according to the method previously described (Settachaimongkon et al., 2014a). NOESY 1D- ${ }^{1} \mathrm{H}-\mathrm{NMR}$ measurements were performed in a $600 \mathrm{MHz}$ NMR spectrometer (Bruker, Rheinstetten, Germany) operated with similar parameters as described by Lu et al. (2013). The ${ }^{1} \mathrm{H}$-NMR spectra were baselinecorrected, phase-corrected, aligned and calibrated based on the internal standard (TSP) peak. For each spectrum, chemical shift $(\delta)$ across the range of $0.00-10.00 \mathrm{ppm}$ was segmented (binning) with an interval of $0.02 \mathrm{ppm}$ (Settachaimongkon et al., 2014a). The signal intensity in each bin was integrated and expressed in arbitrary units using AMIX software (Bruker, Rheinstetten, Germany). Metabolite labels were assigned to the bins by means of Chenomx NMR suite 7.5 library (Chenomx Inc., Alberta, Canada) and from the list of metabolites identified by Settachaimongkon et al. (2014a). For unlabeled bins, significant variables were selected based on one-way ANOVA at 95\% confidence level.

\subsection{Statistical analysis}

ANOVA and multiple comparisons by Tukey's test were performed using IBM-SPSS statistics package version 21 (SPSS Inc., Chicago, IL, USA). A probability at $P<0.05$ was considered statistically significant. Metabolomics data were normalized before multivariate analysis (Settachaimongkon et al., 2014a). Principal component analysis was performed using Multi-Experiment Viewer (MeV) version 4.8 (www.tm4.org/mev/).

\section{Results}

\subsection{Bacterial growth and survival}

Bacterial populations in the samples co-fermented with sublethally precultured L. rhamnosus GG (LGG) and B. animalis subsp. lactis BB12 (BB12) were compared with those in the samples cofermented with standard precultured probiotics (control group) of each strain. In comparison, the effect on growth (increase in biomass) and survival (retention of viability) of probiotics were discussed in terms of increase or decrease in $\log _{10}$ transformed units of viable counts. The main effects of the individual preculturing stress factors, i.e. $\mathrm{NaCl}$ and $\mathrm{pH}$, and their interaction were statistically determined using two-way ANOVA with $2 \times 2$ between subjects factorial design (Table 2).

In co-cultures with LGG (Fig. 1; left panels), growth and survival of yoghurt starters were not significantly affected by the incorporation of sublethally precultured probiotics. At the end of fermentation, the viable counts of S. thermophilus (Fig 1A) and L. delbrueckii subsp. bulgaricus (Fig. 1C) increased by 2.2 and 2.1 log units to reach an average value of $8.5 \pm 0.1$ and $8.1 \pm 0.1 \log \mathrm{CFU} / \mathrm{g}$, respectively. The viable counts of two yoghurt starters remained virtually stable (above $8.0 \log \mathrm{CFU} / \mathrm{g}$ ) throughout the entire duration of storage. Variations in growth and survival of LGG were observed among the control group and their sublethally precultured cells (Fig. 1E \& Table 2). During fermentation, LGG precultured at 2.0\% NaCl-pH 6.5 exhibited the highest increase in viable counts ( 0.8 log increase) while those precultured at $4.0 \% \mathrm{NaCl}-\mathrm{pH} 6.5$ showed the lowest increase ( $0.5 \mathrm{log}$ increase). However, none of the preculturing conditions could significantly enhance $(P>0.05)$ the growth of LGG in milk compared to the control group ( $0.6 \mathrm{log}$ increase). Among the groups of sublethally precultured LGG, the effects of $\mathrm{NaCl}$ and interaction between $\mathrm{NaCl}^{*} \mathrm{pH}$ during preculturing contributed significantly ( $P=0.01$ and 0.02 , respectively) to their growth in milk during set-yoghurt fermentation. The effect of preculturing on the survival of LGG and their sublethally precultured cells during storage was evidently observed. At the end of storage, LGG precultured at $\mathrm{pH} 4.5$ (with either $2.0 \%$ or $4.0 \% \mathrm{NaCl}$ ) showed a significant improvement $(P=0.03)$ on their survival $(0.2$ and $0.3 \mathrm{log}$ reduction, respectively) compared to the control group (0.5 log reduction). On the other hand, the survival of LGG precultured at $4.0 \% \mathrm{NaCl}-\mathrm{pH} 6.5$ was significantly impaired $(P<0.01)(1.2 \mathrm{log}$ reduction). Statistical tests demonstrated that only the main effect of pH during preculturing significantly contributed $(P<0.01)$ to the survival of LGG during storage.

In co-cultures with BB12 (Fig. 1; right panels), growth and survival of $S$. thermophilus (Fig 1B) were not significantly affected by the incorporation of sublethally precultured probiotics. Their viable counts increased by $2.3 \mathrm{log}$ units to reach and average value of $8.5 \pm 0.1 \log \mathrm{CFU} / \mathrm{g}$ at the end of fermentation and remained stable (above $8.0 \log \mathrm{CFU} / \mathrm{g}$ ) throughout the entire duration of storage. On the other hand, the growth of L. delbrueckii subsp. bulgaricus (Fig. 1D) was impaired by co-cultivation with BB12 precultured at $1.5 \% \mathrm{NaCl}$ (with either $\mathrm{pH} 5.0$ or 7.0 ) resulting in significantly lower $(P<0.01)$ viable counts at the end of fermentation $(8.1 \pm 0.1 \log$ 
Table 2

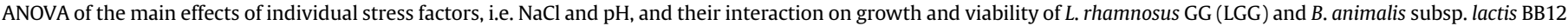
(BB12) in set-yoghurt.

\begin{tabular}{|c|c|c|c|c|c|c|c|c|}
\hline \multirow[t]{3}{*}{ Changes in bacterial population } & \multirow[t]{3}{*}{ Standard LGG (control) } & \multicolumn{4}{|c|}{ Sublethally precultured LGG } & \multicolumn{3}{|c|}{ Test of significance between effects } \\
\hline & & \multicolumn{2}{|l|}{$2.0 \% \mathrm{NaCl}$} & \multicolumn{2}{|l|}{$4.0 \% \mathrm{NaCl}$} & \multicolumn{2}{|c|}{ Main effect } & \multirow{2}{*}{$\frac{\text { Interaction }}{\mathrm{NaCl}^{*} \mathrm{pH}}$} \\
\hline & & $\mathrm{pH} 4.5$ & pH 6.5 & $\mathrm{pH} 4.5$ & $\mathrm{pH} 6.5$ & $\mathrm{NaCl}$ & $\mathrm{pH}$ & \\
\hline $\begin{array}{l}\text { Increase in viable counts during } \\
\text { fermentation (log CFU/g } 4 \mathrm{~h}-\mathrm{Oh})\end{array}$ & $0.6 \pm 0.1 \mathrm{ab}^{\mathrm{a}}$ & $0.7 \pm 0.0 \mathrm{ab}$ & $0.8 \pm 0.1 b$ & $0.7 \pm 0.1 \mathrm{ab}$ & $0.5 \pm 0.1 \mathrm{a}$ & $P=0.01$ & $P>0.05$ & $P=0.02$ \\
\hline \multirow{4}{*}{$\begin{array}{l}\text { Decrease in viable counts during } \\
\text { storage }(\log C F U / g 28 d-4 h)\end{array}$} & $-0.5 \pm 0.0 \mathrm{~b}$ & $-0.2 \pm 0.1 \mathrm{a}$ & $-0.8 \pm 0.3 b c$ & $-0.3 \pm 0.1 \mathrm{a}$ & $-1.2 \pm 0.3 c$ & $P>0.05$ & $P<0.01$ & $P>0.05$ \\
\hline & Standard BB12 (control) & \multicolumn{4}{|c|}{ Sublethally precultured BB12 } & \multicolumn{3}{|c|}{ Test of significance between effects } \\
\hline & & \multicolumn{2}{|l|}{$0.5 \% \mathrm{NaCl}$} & \multicolumn{2}{|l|}{$1.5 \% \mathrm{NaCl}$} & \multicolumn{2}{|c|}{ Main effect } & Interaction \\
\hline & & pH 5.0 & pH 7.0 & pH 5.0 & pH 7.0 & $\mathrm{NaCl}$ & $\mathrm{pH}$ & $\mathrm{NaCl}^{*} \mathrm{pH}$ \\
\hline $\begin{array}{l}\text { Increase in viable counts during } \\
\text { fermentation (log CFU/g } 4 \mathrm{~h}-0 \mathrm{~h})\end{array}$ & $0.9 \pm 0.2 b$ & $1.1 \pm 0.1 b$ & $1.0 \pm 0.0 \mathrm{~b}$ & $0.3 \pm 0.1 \mathrm{a}$ & $0.4 \pm 0.2 \mathrm{a}$ & $P<0.01$ & $P>0.05$ & $P>0.05$ \\
\hline $\begin{array}{l}\text { Decrease in viable counts during } \\
\text { storage }(\log C F U / g 28 d-4 h)\end{array}$ & $-1.2 \pm 0.2 \mathrm{~d}$ & $-0.5 \pm 0.0 \mathrm{~b}$ & $-0.8 \pm 0.1 c$ & $-0.3 \pm 0.0 \mathrm{a}$ & $-0.6 \pm 0.0 b$ & $P<0.01$ & $P<0.01$ & $P>0.05$ \\
\hline
\end{tabular}

${ }^{a}$ Letters $(a-d)$ indicate significant difference $(P<0.05)$ among means within the same row.
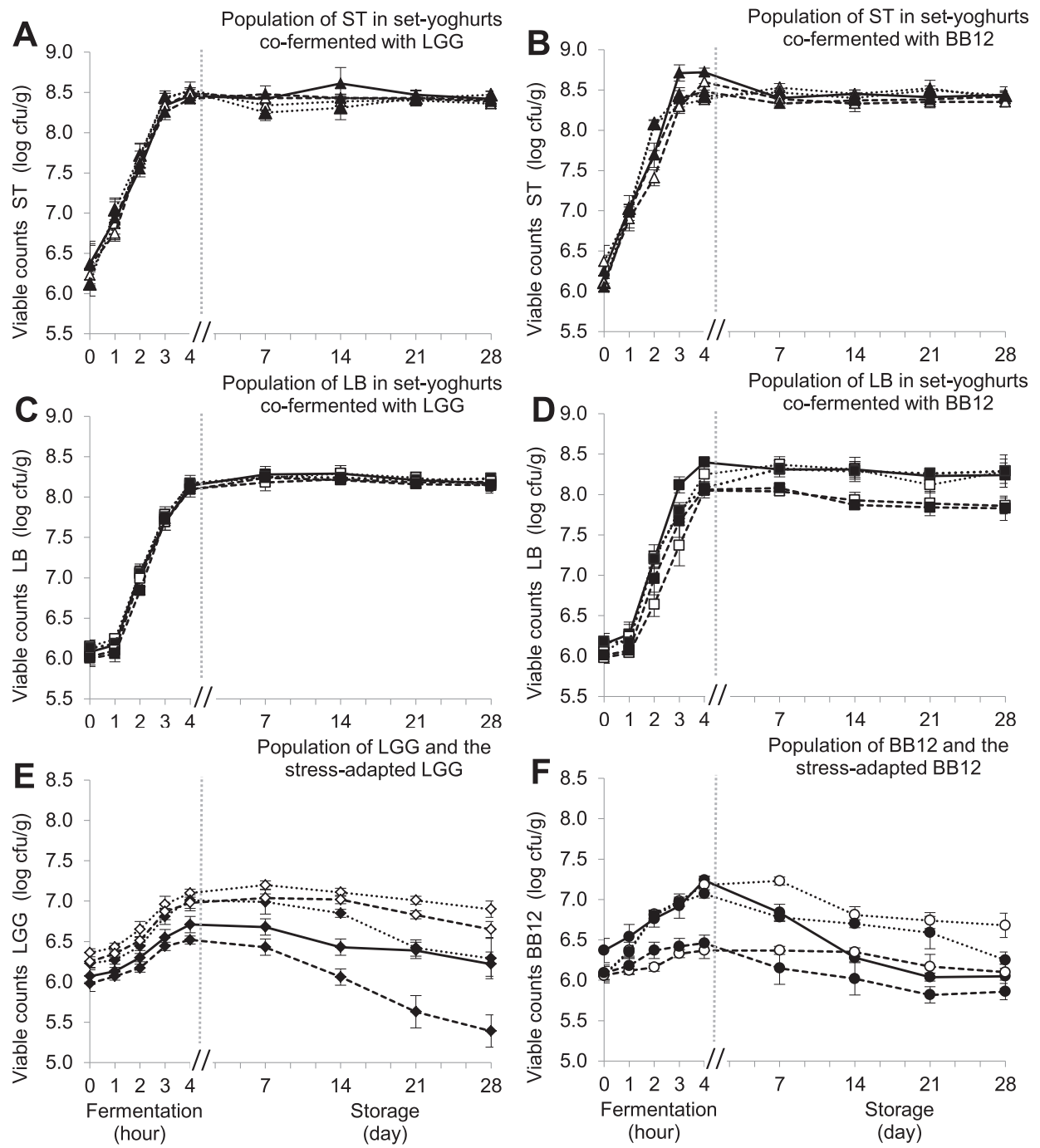

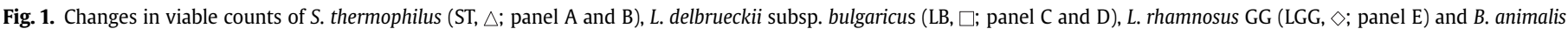

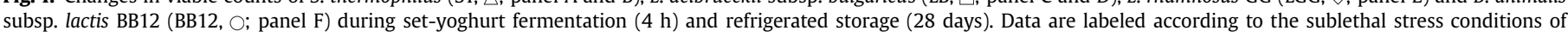

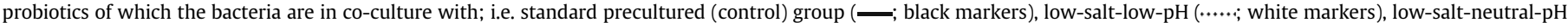

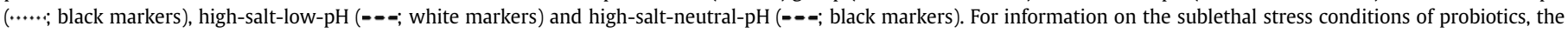
reader is referred to Table 1. Error bars represent standard deviations based on three replicates. 
$\mathrm{CFU} / \mathrm{g})$ compared to the control group $(8.4 \pm 0.1 \log \mathrm{CFU} / \mathrm{g})$. Although the survival of $L$. delbrueckii subsp. bulgaricus during storage was not affected ( $\mathrm{ca} .0 .1 \mathrm{log}$ reduction) by co-cultivation with BB12 precultured at $1.5 \% \mathrm{NaCl}$ (with either $\mathrm{pH} 5.0$ or 7.0 ), the initially lower viable counts at $4 \mathrm{~h}$ subsequently resulted in significantly lower $(P=0.02)$ viable counts at the end of storage $(7.8 \pm 0.2 \log \mathrm{CFU} / \mathrm{g}$ ) compared to the control group $(8.3 \pm 0.2 \log \mathrm{CFU} / \mathrm{g})$. Variations in growth and survival of BB12 were observed among the control group and their sublethally precultured cells (Fig. 1F \& Table 2). During fermentation, it was evident that the growth of $\mathrm{BB} 12$ precultured at $1.5 \% \mathrm{NaCl}$ (with either $\mathrm{pH} 5.0$ or 7.0 ) (0.4 log increase) was significantly impaired $(P<0.01)$ while the growth of $\mathrm{BB} 12$ precultured at $0.5 \% \mathrm{NaCl}$ (with either pH 5.0 or 7.0 ) (1.1 log increase) was not significantly affected $(P>0.05)$ compared to the control group (0.9 log increase). Among the groups of sublethally precultured BB12, statistical tests demonstrated that only the main effect of $\mathrm{NaCl}$ contributed significantly $(P<0.01)$ to their growth impairment during setyoghurt fermentation. An effect of preculturing on the survival of BB12 and their sublethally precultured cells during refrigerated storage was also observed. At the end of storage, all sublethally precultured BB12 showed a significant improvement $(P<0.05)$ (max. $0.8 \mathrm{log}$ reduction) in their survival compared to the control group (1.2 log reduction). Interestingly, the viable counts of BB12 precultured at $1.5 \% \mathrm{NaCl}$ (with either $\mathrm{pH} 5.0$ or 7.0 ) which were significantly impaired during fermentation decreased relatively slow during storage ( 0.3 and $0.6 \log$ reduction, respectively). The two main effects of $\mathrm{NaCl}$ and $\mathrm{pH}$ (without interaction) during preculturing contributed significantly $(P<0.01)$ to the survival of BB12 during storage.

\subsection{Acidification profiles}

In the samples co-fermented with LGG and their sublethally precultured cells (Fig. S1A), similar pH decrease patterns were observed during fermentation throughout the entire duration of storage. The average $\mathrm{pH}$ values of all samples were not significantly different $(P>0.05)$ either at the end of fermentation $(4.4 \pm 0.1)$ or the end of storage $(4.0 \pm 0.1)$. In the samples co-fermented with BB12 and their sublethally precultured cells (Fig. S1C), similar pH decrease patterns were observed during fermentation resulting in an average value of $4.4 \pm 0.1$ at $4 \mathrm{~h}$. During storage, co-fermentation with standard precultured BB12 and BB12 precultured at $0.5 \% \mathrm{NaCl}$ (with either $\mathrm{pH} 5.0$ or 7.0 ) showed similar $\mathrm{pH}$ decrease patterns with an average value of $4.1 \pm 0.1$ while a small deviation in $\mathrm{pH}$ reduction was observed in the samples co-fermented with BB12 precultured at $1.5 \% \mathrm{NaCl}$ (with either $\mathrm{pH} 5.0$ or 7.0 ) resulting in an average $\mathrm{pH}$ value of $4.3 \pm 0.1$ at the end of storage. However, the difference was not statistically significant $(P>0.05)$.

The titratable acidity, expressed as \% equivalent lactic acid ( $w /$ $\mathrm{w}$ ), was subtracted by its initial value in the sample at $0 \mathrm{~h}$ (unfermented milk) and presented as titratable acidity produced by bacterial activity. In the samples co-fermented with LGG and their sublethally precultured cells (Fig. S1B), there was no significant difference $(P>0.05)$ in titratable acidity either at the end of fermentation $(0.70 \pm 0.02 \%)$ or the end of storage $(1.07 \pm 0.05 \%)$. In the samples co-fermented with BB12 and their sublethally precultured cells (Fig. S1D), there was also no significant difference in titratable acidity during fermentation $(0.67 \pm 0.03 \%)$. However, a lower acid production during storage was observed in the samples co-fermented with $\mathrm{BB} 12$ precultured at $1.5 \% \mathrm{NaCl}$ (with either pH 5.0 or 7.0). These two cultures resulted in a lower titratable acidity $(0.93 \pm 0.02 \%)$ compared to the control group $(1.02 \pm 0.06 \%)$. This finding is in accordance with the $\mathrm{pH}$ decrease patterns found in these two sublethally precultured BB12 cultures.
Although the difference seemed to be negligible, the final titratable acidity of the samples co-fermented with BB12 precultured at $1.5 \% \mathrm{NaCl}-\mathrm{pH} 7.0$ was significantly different $(P=0.02)$ from the control group.

\subsection{Volatile metabolite profiles determined by headspace SPME- GC/MS}

Volatile metabolite profiles of set-yoghurts were evaluated at the end of fermentation $(4 \mathrm{~h})$ and every two weeks during storage (14 d and $28 \mathrm{~d}$ ). According to the method described in our previous study (Settachaimongkon et al., 2014a), set-yoghurt was directly fermented in GC vials. The advantages of this approach are the small amount of sample required $(3 \mathrm{~mL})$ together with prevention of volatile loss during sample preparation. A total of 35 volatile metabolites consisting of alcohols, carbonyl compounds, organic acids, sulfur compounds and heterocyclic compound were identified (Table S1). These compounds were introduced as variables for multivariate analysis. If necessary, missing values were replaced by the median of respective metabolites. Samples from three replicates of each type of starter combination were statistically treated as individual objects. Principal component analysis (PCA) was performed to distinguish the volatile metabolite profiles of set-yoghurts co-fermented with standard precultured probiotics and their sublethally precultured cells within the same species.

For the samples co-fermented with LGG and their sublethally precultured cells (Fig. 2), an overall PCA score plot was constructed with a total variance of $45.5 \%(n=45)$ (Fig. $2 A)$. Volatile metabolite profiles of the samples at $4 \mathrm{~h}$ could be well distinguished from those of stored samples along PC1 (27.1\% variance). The PC-loading indicated which metabolites were accountable for discrimination. It can be seen that 1-methoxy-2-propanol is determinant for the $4 \mathrm{~h}$ samples while 2,3-pentanedione, dimethyl disulfide, 2heptanone, acetic acid and dimethyl sulfone are accountable for discrimination of stored samples. For better comparison, two separated PCA score plots were constructed for distinguishing among samples at $4 \mathrm{~h}(\mathrm{n}=15)$ with a total variance of $58.7 \%$ (Fig. 2B) and among stored samples $(\mathrm{n}=30)$ with a total variance of $47.1 \%$ (Fig. 2C). At the end of fermentation, volatile metabolite profiles of the samples co-fermented with sublethally precultured LGG were clearly distinguished from each other as well as from the control group with an exception for those of $4.0 \% \mathrm{NaCl}-\mathrm{pH} 4.5$ which showed an overlap with the control group. The samples cofermented with LGG precultured at pH 4.5 (with either $2.0 \%$ or $4.0 \% \mathrm{NaCl}$ ) were distinguished from the other groups along PC2 (24.5\% variance). The PC2-loading indicated that the majority of volatile metabolites especially 2-heptanone, 3-pentanone, acetic acid and hexanoic acid were accountable for the separation of samples co-fermented with LGG precultured at $\mathrm{pH} 4.5$ (with either $2.0 \%$ or $4.0 \% \mathrm{NaCl}$ ) while 2-butanone, 1-methoxy-2-propanol, 2methyl-1-butanol and 2-ethylhexanol were accountable for the separation of samples co-fermented with standard precultured LGG and LGG precultured at $4.0 \% \mathrm{NaCl}-\mathrm{pH}$ 6.5. During storage, it was remarkable that the volatile metabolite profiles of samples cofermented with different types of sublethally precultured LGG became less isolated. Nevertheless, the samples co-fermented with LGG precultured at $2 \% \mathrm{NaCl}$ (with either $\mathrm{pH} 4.5$ or 6.5 ) were still clearly distinguished from the other groups along PC2 (22.9\% variance). The PC2-loading indicated that ethanol, 1butanol, 2-methyl-1-butanol, 3-methyl-2-butenal and acetoin contributed to the separation of samples co-fermented with LGG precultured at $2 \% \mathrm{NaCl}$ (with either $\mathrm{pH} 4.5$ or 6.5 ) while dimethyl disulfide and 1-methoxy-2-propanol accounted for the separation of the other groups. 

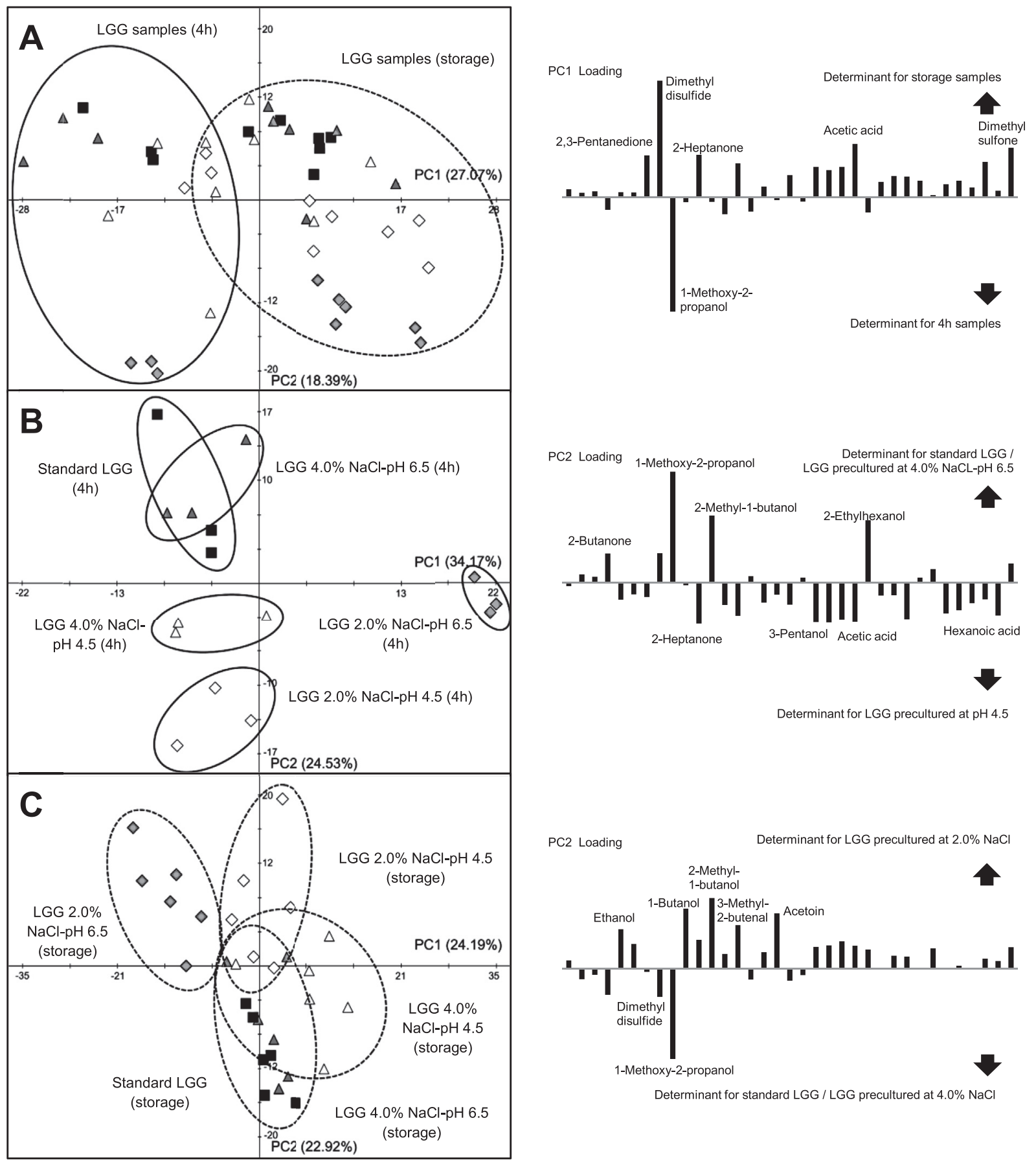

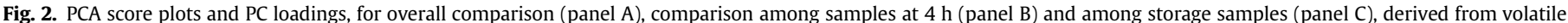

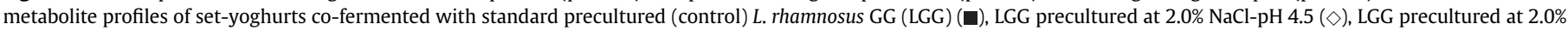
$\mathrm{NaCl}-\mathrm{pH} 6.5(\diamond)$, LGG precultured at 4.0\% NaCl-pH $4.5(\triangle)$ and LGG precultured at $4.0 \% \mathrm{NaCl}-\mathrm{pH} 6.5(\Delta)$.

For the samples co-fermented with BB12 and their sublethally precultured cells (Fig. 3), an overall PCA score plot was constructed with a total variance of $64.5 \%(n=45)$ (Fig. $3 A)$. Volatile metabolite profiles of the samples at $4 \mathrm{~h}$ could be well distinguished from those of stored samples along PC1 (41.8\% variance). The PC1loading indicated that dimethyl sulfide and 1-methoxy-2propanol were determinant of the samples at $4 \mathrm{~h}$ while 2,3pentanedione, dimethyl disulfide and 2-heptanone were determinant for discrimination of stored samples. For better comparison, two separated PCA score plots were constructed for distinguishing among samples at $4 \mathrm{~h}(\mathrm{n}=15)$ with a total variance of $62.1 \%$
(Fig. 3B) and among stored samples $(\mathrm{n}=30)$ with a total variance of $67.9 \%$ (Fig. 3C). At the end of fermentation, volatile metabolite profiles of the samples co-fermented with sublethally precultured BB12 were clearly distinguished from each other as well as from the control group. However, the samples co-fermented with BB12 precultured at $0.5 \% \mathrm{NaCl}-\mathrm{pH} 7.0$ were not clearly separated from the control group. According to the adverse effect on the growth of BB12 in milk, the samples co-fermented with BB12 precultured at $1.5 \% \mathrm{NaCl}$ (with either $\mathrm{pH} 5.0$ or 7.0 ) were distinguished from the other groups along PC1 (42.3\% variance). The PC1-loading indicated that acetic acid, 2-methyl-propanoic acid, butyric acid, 3-methyl 

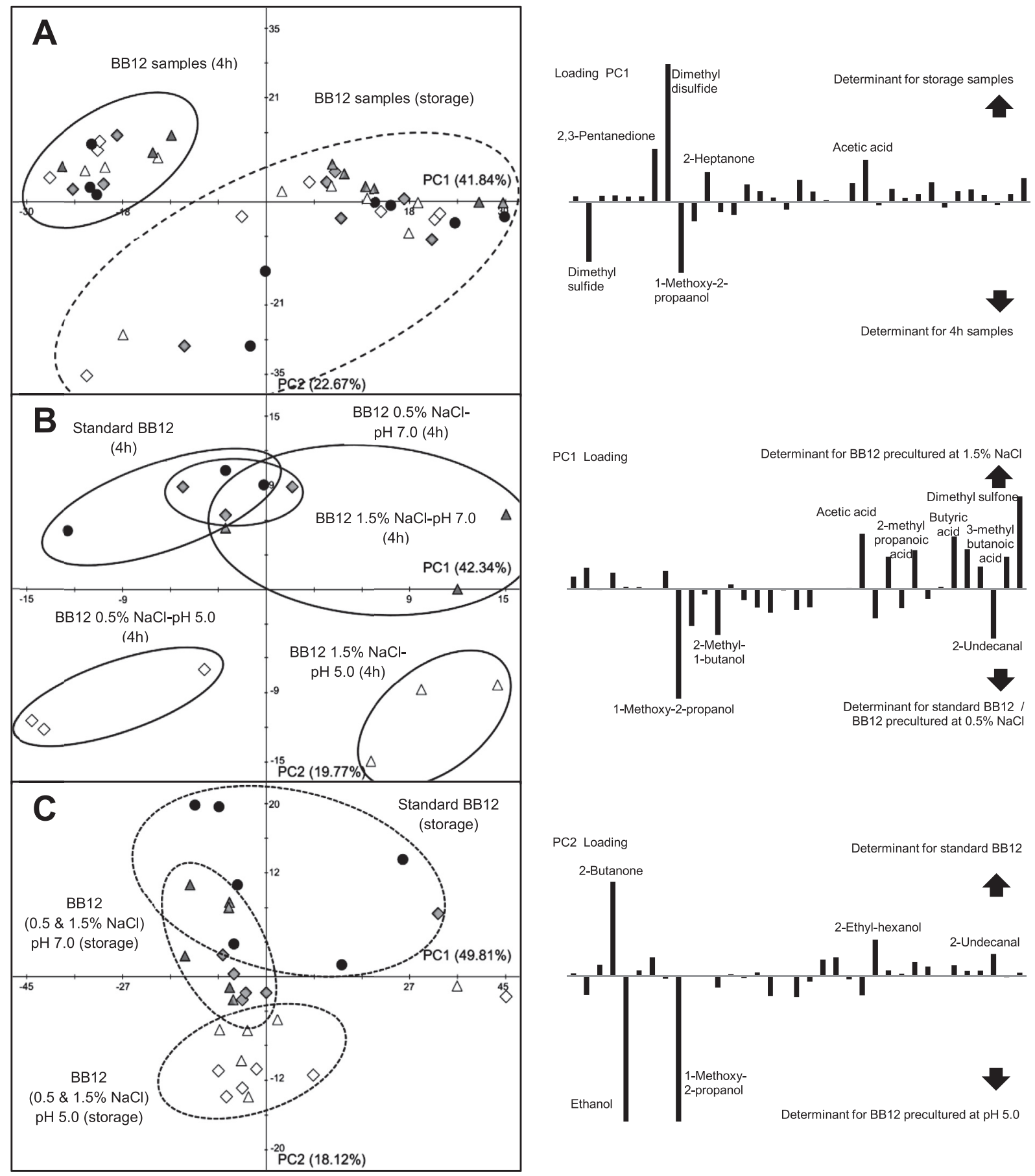

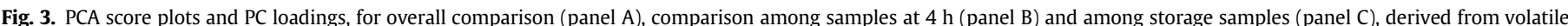

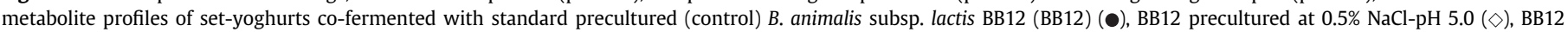
precultured at $0.5 \% \mathrm{NaCl}-\mathrm{pH} 7.0(\diamond), \mathrm{BB} 12$ precultured at $1.5 \% \mathrm{NaCl}-\mathrm{pH} 5.0(\triangle)$ and $\mathrm{BB} 12$ precultured at $1.5 \% \mathrm{NaCl}-\mathrm{pH} 7.0(\triangle)$.

butanoic acid and dimethyl sulfone were the major volatile metabolites accountable for discrimination. The difference in metabolite profiles of sublethally precultured BB12 at the same $\mathrm{pH}$ level (with either $0.5 \%$ or $1.5 \% \mathrm{NaCl}$ ) largely disappeared during storage. A clear distinction between the samples co-fermented with BB12 precultured at $\mathrm{pH} 5.0$ (with either $0.5 \%$ or $1.5 \% \mathrm{NaCl}$ ) and the control group was observed along PC2 while those co-fermented with BB12 precultured at $\mathrm{pH} 7.0$ (with either $0.5 \%$ or $1.5 \% \mathrm{NaCl}$ ) were situated between these two groups. The PC2-loading indicated that ethanol and 1-methoxy-2-propanol accounted for the separation of the samples co-fermented with BB12 precultured at $\mathrm{pH} 5.0$ (with either $0.5 \%$ or $1.5 \% \mathrm{NaCl}$ ) while 2-butanone, 2-ethylhexanol and 2-undecanal contributed to those co-fermented with standard precultured BB12.

\subsection{Non-volatile polar metabolite profiles determined by ${ }^{1} \mathrm{H}-\mathrm{NMR}$}

For non-volatile polar metabolite profiling, NOESY-1D- ${ }^{1} \mathrm{H}-\mathrm{NMR}$ spectra of set-yoghurt were processed according to the method described in our previous study (Settachaimongkon et al., 2014a). A 
total of 43 metabolites including amino acids, carbohydrates, organic acids, lipid derivatives, carbonyl compounds, a sulfur compound and a nucleoside were identified. Quantification was achieved by summation of signal intensities in all bins corresponding to the respective metabolite (Park et al., 2013) and expressed in $\log _{10}$ transformed values (arbitrary unit) (Table S2). For multivariate analysis, it should be mentioned that the 43 identified metabolites accounted for labeling of 149 bins. A complementary data filtering by ANOVA was performed for selection of the remaining unknowns (Lamanna et al., 2011). A total of 218 (LGG) and 164 (BB12) bins were finally introduced as variables for comparison within the same species of probiotics.

For the samples co-fermented with LGG and their sublethally precultured cells, an overall PCA score plot was constructed with a total variance of $67.7 \%(n=20)$ (Fig. 4). Non-volatile polar metabolite profiles of the samples at $4 \mathrm{~h}$ could be completely distinguished from those of stored samples along PC1 (43.7\% variance). At the end of fermentation, the samples co-fermented with LGG precultured at $2.0 \% \mathrm{NaCl}$ (with either $\mathrm{pH} 4.5$ or 6.5 ) and LGG precultured at $4.0 \% \mathrm{NaCl}-\mathrm{pH} 4.5$ were clearly distinguished from those of standard precultured LGG and LGG precultured at $4.0 \% \mathrm{NaCl}-\mathrm{pH}$ 6.5 along PC2 (24.1\% variance). Among stored samples, the same distinction pattern remained, except for the samples co-fermented with LGG precultured at $4.0 \% \mathrm{NaCl}-\mathrm{pH} 6.5$ which showed an overlap between the two major groups. The PC2-loading indicated that most metabolites in amino acid regions, lactate, citrate, oxoglutarate and pyruvate accounted for the separation of samples cofermented with standard precultured LGG and LGG precultured at $4.0 \% \mathrm{NaCl}-\mathrm{pH} 6.5$ while succinate and metabolites in the sugar region contributed to the separation of LGG precultured at $2.0 \% \mathrm{NaCl}$ (with either $\mathrm{pH} 4.5$ or 6.5 ) and $4.0 \% \mathrm{NaCl}-\mathrm{pH} 4.5$.

For the samples co-fermented with BB12 and their sublethally precultured cells, an overall PCA score plot was constructed with a total variance of $72.9 \%(n=20)$ (Fig. 5A). Complete separation between non-volatile polar metabolite profiles of the samples at $4 \mathrm{~h}$ and stored samples was not observed, although the two groups could be distinguished along PC2 (17.0\% variance). For further comparison, two separated PCA score plots were constructed for distinguishing among samples at $4 \mathrm{~h}(\mathrm{n}=10)$ with a total variance of $77.5 \%$ (Fig. $5 B$ ) and among stored samples $(n=10)$ with a total variance of $83.8 \%$ (Fig. 5C). At the end of fermentation, the samples co-fermented with BB12 precultured at $0.5 \% \mathrm{NaCl}-\mathrm{pH} 5.0$ and $1.5 \%$ $\mathrm{NaCl}$ (with either pH 5.0 or 7.0) were clearly distinguished from those of standard precultured BB12 and BB12 precultured at 0.5\%
NaCl-pH 7.0 along PC1 (60.6\% variance). The PC1-loading indicated that most of metabolites in amino acid and sugar regions were accountable for discrimination of the latter two groups. As storage time progressed, it was evident that the distinction among samples co-fermented with different types of sublethally precultured BB12 became less apparent.

\section{Discussion}

The vigorous growth and good retention of survival of $S$. thermophilus C44 and L. delbrueckii subsp. bulgaricus C49 during setyoghurt fermentation and refrigerated storage have been discussed previously (Settachaimongkon et al., 2014b). In co-cultures with sublethally precultured probiotics, it was remarkable that the growth of $L$. delbrueckii subsp. bulgaricus during fermentation was significantly impaired by co-culturing with BB12 precultured at $1.5 \% \mathrm{NaCl}$. It has been documented that bifidobacteria are inhibitory to a wide range of microorganisms due to the production of lactic and acetic acids as a part of their carbohydrate metabolism (Reis et al., 2012). Moreover, various antimicrobial substances such as bacteriocins produced by bifidobacteria have been found to possess potent antimicrobial activities towards closely related species as well as towards lactobacilli (Cheikhyoussef et al., 2008; Martinez et al., 2013). The activity of a bacteriocin produced by $B$. animalis subsp. lactis BB12 (known as biflact Bb12) has been reported (Martinez et al., 2013; Saleh and El-Sayed, 2004). A number of environmental factors including composition of the culture medium, nutrient shortage as well as the presence of other competing microorganisms play an important role in regulation of bacteriocin production in bifidobacteria (Martinez et al., 2013). In our study, however, co-culturing with BB12 precultured at $1.5 \%$ $\mathrm{NaCl}$ resulted in a lower titratable acidity compared to the control group. Possibly, preculturing at $1.5 \% \mathrm{NaCl}$ triggers the synthesis of certain compounds in BB12 which provide a slight inhibitory effect on the growth of $L$. delbrueckii subsp. bulgaricus during set-yoghurt fermentation. This effect is interesting and requires further investigation.

For several probiotic bacteria, it has been documented that stress responses vary as a function of the growth phase, i.e. cells in stationary phase develop more general resistance to various types of stresses (Saarela et al., 2004; Waddington et al., 2010). Therefore, the preculturing period in this study was prolonged for $24 \mathrm{~h}$, allowing the development of adaptive stress responses in the probiotic cells in stationary growth phase. Adaptive stress
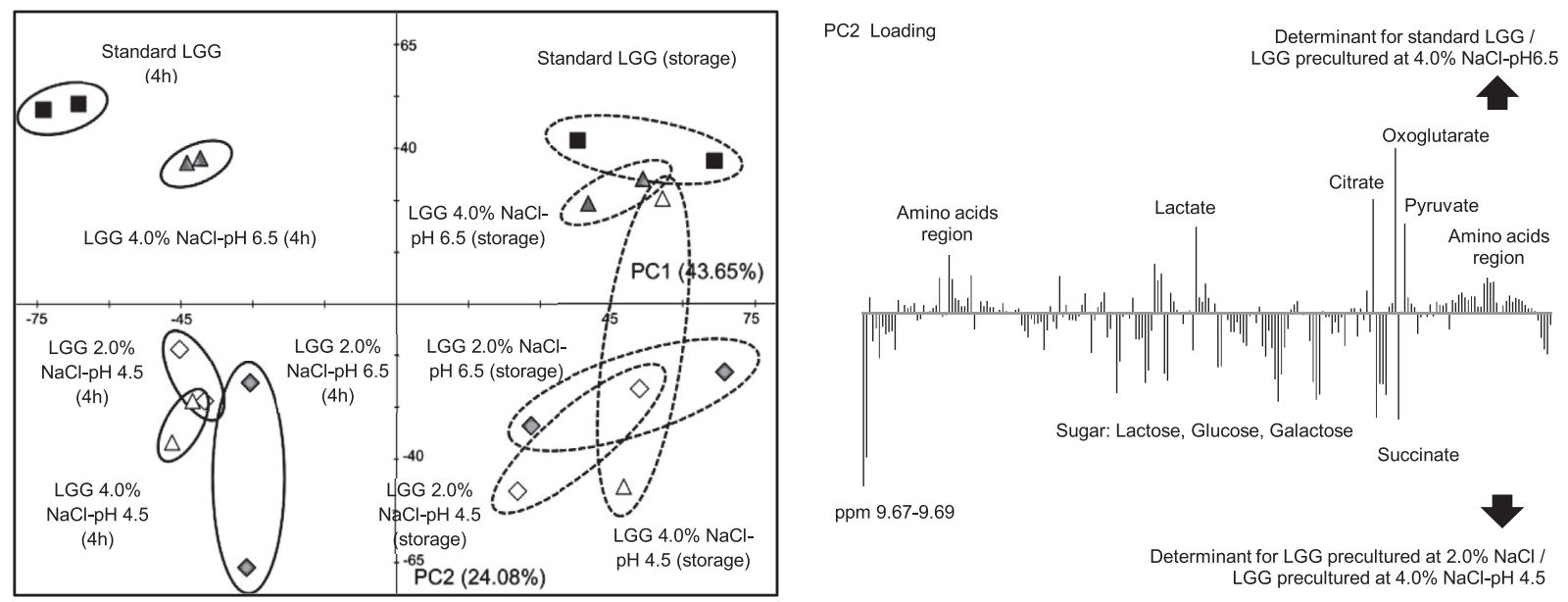

Determinant for LGG precultured at $2.0 \% \mathrm{NaCl} /$ LGG precultured at $4.0 \% \mathrm{NaCl}-\mathrm{pH} 4.5$

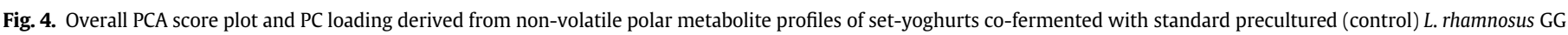

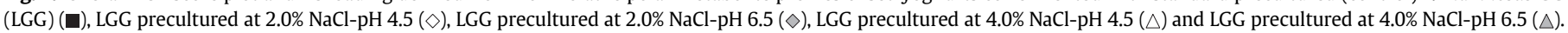




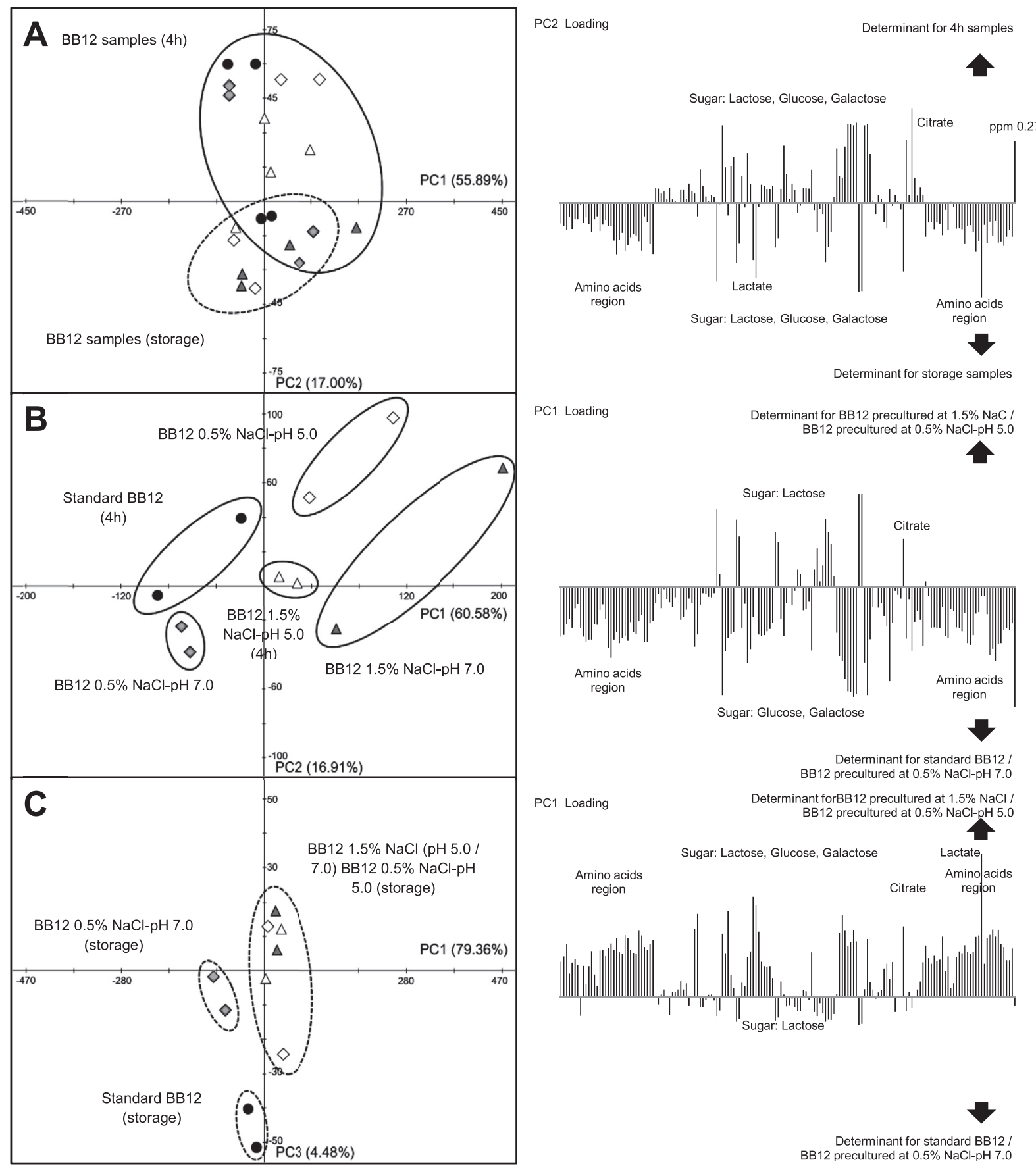

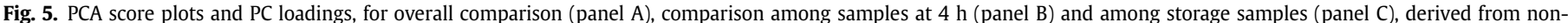

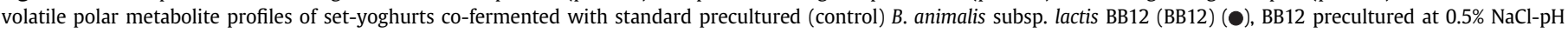
$5.0(\diamond), \mathrm{BB} 12$ precultured at $0.5 \% \mathrm{NaCl}-\mathrm{pH} 7.0(\diamond), \mathrm{BB} 12$ precultured at $1.5 \% \mathrm{NaCl}-\mathrm{pH} 5.0(\triangle)$ and $\mathrm{BB} 12$ precultured at $1.5 \% \mathrm{NaCl}-\mathrm{pH} 7.0(\triangle)$.

responses in probiotics are associated with the alteration of various physiological features (Van de Guchte et al., 2002). A better survival of probiotics under acidic conditions is induced by physiological adaptation known as acid tolerance response (ATR) (Van de Guchte et al., 2002). The ATR associated mechanisms primarily include (i) $\mathrm{pH}$ homeostasis by proton-translocating $\mathrm{F}_{1} \mathrm{~F}_{0}$-ATPase, (ii) alteration of cell membrane properties by modification in fatty acid composition, (iii) increase of alkalinity of cytoplasm by the activity of arginine deiminase, urease and glutamine decarboxylase and (iv) production of several stress proteins (De Angelis and Gobbetti, 2004; Ruiz et al., 2011; Van de Guchte et al., 2002). The response to osmotic stress results in the accumulation of compatible solutes and activation of membrane associated proteins for maintaining turgor pressure of the cell (Serrazanetti et al., 2009). The results in this study demonstrated adaptive responses of LGG and BB12 to sublethal $\mathrm{NaCl}-\mathrm{pH}$ conditions, especially at relatively low $\mathrm{pH}$ value, in terms of viability improvement in yoghurt during refrigerated storage. This finding supports the hypothesis that pre-adaptation can enhance the survival of probiotics in a food system (Ross et al., 2005; Saarela et al., 2004; Sánchez et al., 2012; Shah, 2000). However, this is in contradiction with the work of Maus and Ingham (2003) who found an equal acid tolerance between 
pretreated (combination of temperature, starvation time and $\mathrm{pH}$ stress) and untreated cells of Bifidobacterium lactis in yoghurt during refrigerated storage. These authors suggested that yoghurt fermentation process may override any previous enhancement in acid-tolerance achieved during preculturing (Maus and Ingham, 2003). Nevertheless, it is well documented that adaptive responses in probiotics are highly strain-dependent and vary largely according to the type of stresses exposed as well as experimental conditions (Maus and Ingham, 2003; Mozzetti et al., 2013; Saarela et al., 2004). Interestingly, the viable cells of BB12 precultured at $1.5 \% \mathrm{NaCl}$ showed a significant improvement in survival during storage, although their growth was significantly impaired during fermentation. It has been reported that alteration in certain cellular protective mechanisms induced by adaptive stress responses may provide an adverse effect on bacterial growth (Van de Guchte et al., 2002). At the end of storage, it should be mentioned that the final viable counts of probiotics in this study, except for those precultured at high-NaCl-neutral-pH condition, still remain above the minimum recommended level (6.0 $\log \mathrm{CFU} / \mathrm{g}$ ) to ensure their potential health-promoting effects (Shiby and Mishra, 2013).

Acidification profiles of set-yoghurts were not significantly affected by either the different strains of probiotics or the preculturing conditions. However, a small deviation in $\mathrm{pH}$ decrease pattern resulting in slightly lower titratable acidity at the end of storage was observed in the samples co-fermented with BB12 precultured at $1.5 \% \mathrm{NaCl}$. The reduction of $\mathrm{pH}$ and accumulation of organic acids during refrigerated storage of fermented milk are defined as "post-acidification" which is mainly attributed to the ongoing metabolic activity of L. delbrueckii subsp. bulgaricus (Shah, 2000). Accordingly, the slightly lower post-acidification found in yoghurts co-fermented with BB12 precultured at $1.5 \% \mathrm{NaCl}$ could be associated with the significant impairment on the viable counts of L. delbrueckii subsp. bulgaricus as discussed previously.

It is well documented that environmental stresses induce alterations in the metabolic activity of probiotics leading to substantial changes in their technological and functional performances (Ruiz et al., 2011; Serrazanetti et al., 2009; Tsakalidou and Papadimitriou, 2011). As a result, a broader variety of metabolites can be formed which may considerably influence the biochemical and organoleptic characteristics of the fermented product (Serrazanetti et al., 2009). PCA results in this study confirm the impact of metabolic activity of stress-adapted LGG and BB12 on the volatile and non-volatile metabolite profile of yoghurt. The distinct patterns suggest that volatile metabolite profiles of the samples cofermented with LGG can be distinguished according to either acid stress or osmotic stress while those of the samples co-fermented with BB12 can only be distinguished according to acid stress. Furthermore, it was remarkable that distinct volatile metabolite profiles of the samples co-fermented with different types of sublethally precultured probiotics at the end of fermentation gradually merged during storage. An explanation for this could be that the ongoing metabolic activity of starter cultures, mainly by L. delbrueckii subsp. bulgaricus as discussed earlier in post-acidification, contributed to the production of volatile metabolites during refrigerated storage. This could also be associated with the population size of the yoghurt starters, especially during storage, which were approximately ten to hundred-times higher compared to those of the probiotic adjuncts. Thus, the influence on volatile metabolite profiles caused by the metabolic activity of stress adapted probiotics during fermentation most likely was obscured. Regarding the non-volatile metabolite profiles, the numbers of significant variables (bin) filtered by ANOVA suggested that nonvolatile metabolite profiles among the LGG groups (218 bins) were rather dissimilar compared to those of BB12 (164 bins). This was clearly confirmed by the patterns of PCA. Non-volatile metabolite profiles of the samples co-fermented with LGG can be distinguished according to osmotic stress. Indeed, it should be noted that the separated patterns are in accordance with those previously observed for their volatile metabolite profiles. Unlike the situation of LGG, non-volatile metabolite profiles of the samples co-fermented with BB12 could not be clearly distinguished. The PCA results demonstrate that the effect of sublethal stress responses during preculturing on the metabolome of set-yoghurt is species-specific. To our knowledge, this is the first time that a combined metabolomics approach followed by multivariate analysis has been applied to understand the relation between preadaptation and technological performances of probiotics in food systems.

The contributions of yoghurt starters, LGG and BB12 to the biochemical conversion of milk components, i.e. production of aroma volatile and non-volatile metabolites, during fermentation and refrigerated storage of fermented milk have been extensively reported (Cheng, 2010; Østlie et al., 2003; Tamime and Robinson, 2007; Urbach, 1995) and discussed in our previous study (Settachaimongkon et al., 2014b). Regarding the influence of sublethal preculturing, it has been documented that the ATR in lactobacilli and bifidobacteria is associated with certain metabolic changes, especially the function of enzymes involved in glycolysis and pyruvate metabolism (Ruiz et al., 2011; Sánchez et al., 2012). The results showed that acetic acid, acetoin, 2-butanone and ethanol were accountable for the separation of yoghurt samples cofermented with sublethally precultured probiotics. An increase in the production of these metabolites could be correlated with a higher yield of ATP for supporting the $\mathrm{pH}$ homeostasis by $\mathrm{F}_{1} \mathrm{~F}_{0^{-}}$ ATPase (Sánchez et al., 2007). Furthermore, a higher concentration of several enzymes involved in the biosynthesis of branched-chain amino acids as well as sulfur amino acids was reported to be associated with ATR (Sánchez et al., 2007). Our results showed an effect of sublethally precultured probiotics on the content of various volatiles derived from the catabolism of these amino acids in yoghurt; i.e. 1-methoxy-2-propanol (Val), 2-methyl-1-butanol (Ile/Leu), 3-methyl-2-butenal (Ile/Leu), 3-methyl-butanoic acid (Leu), 2-methyl-propanoic acid (Val) and sulfur compounds (Cys/ Met) (Ardö, 2006). According to the quantification of non-volatile metabolites (Table S2), a lower concentration of pyruvate and a higher concentration of acetate, formate, isoleucine, leucine and valine were clearly observed in the samples co-fermented with sublethally precultured LGG compared to BB12. This observation could be associated with a good distinction in their metabolite profiles revealed by PCA. In terms of technological relevance, variations in these compounds may considerably influence the organoleptic quality of product (Clark, 2009). For example, an excessive concentration of acetic acid causes a vinegar-like pungent flavor and masks the flavor-notes from other aroma compounds in yoghurt (Clark, 2009). In future research, the absolute concentration of these indicative volatile metabolites should be quantified. This will show whether the concentration of these compounds is still present within the same concentration ranges as normally detected in commercial products. Based on this information, the potential impact on the organoleptic quality of yoghurt could be properly predicted (Settachaimongkon et al., 2014b). Besides this, an additional research focusing on sensory evaluation of yoghurt with trained panelists is also recommended.

\section{Conclusions}

The present study demonstrated that preculturing of LGG and BB12 under sublethal salt $(\mathrm{NaCl})$ and $\mathrm{pH}$ stress did not significantly enhance their growth during set-yoghurt fermentation. On the other hand, the survival of probiotics during refrigerated storage 
could be successfully improved specifically by preculturing at relatively low $\mathrm{pH}$ value. Preculturing at $2.0 \% \mathrm{NaCl}-\mathrm{pH} 4.5$ and $0.5 \%$ $\mathrm{NaCl}-\mathrm{pH} 5.0$ provided the most significant improvement on the survival of LGG and BB12, respectively. A complementary metabolomics approach using SPME-GC/MS and ${ }^{1} \mathrm{H}-\mathrm{NMR}$ combined with multivariate analysis revealed substantial impact of preculturing of probiotics on volatile and non-volatile polar metabolite formation in set-yoghurt. Moreover, various aroma volatile compounds indicated in loading plots suggested that incorporation of stressadapted probiotics might considerably influence the organoleptic quality of yoghurt. The results demonstrate that adaptive responses of LGG and BB12 to sublethal salt and low pH stress conditions not only affect their survival during yoghurt production but also lead to substantial changes in the metabolite composition of the fermented product. This study provides new information on the application of stress-adapted probiotics in an actual food-carrier environment.

\section{Acknowledgments}

This research was conducted under CHE-PhD-SFR-2551 scholarship granted by the Commission on Higher Education of the Royal Thai Government. Yoghurt starters were kindly provided by Bert Hafkamp from CSK Food Enrichment. The authors are grateful to Dr. Kasper Hettinga, Geert Meijer, Dr. Elsa Antunes Fernandes and Dr. Jacques Vervoort for assistance in GC/MS and NMR analysis. We also thank Maciek Spus, Anastasia Emelianova and Wu Qu for technical contributions.

\section{Appendix A. Supplementary data}

Supplementary data related to this article can be found at http:// dx.doi.org/10.1016/j.fm.2015.01.011.

\section{References}

Ardö, Y., 2006. Flavour formation by amino acid catabolism. Biotechnol. Adv. 24, $238-242$.

Cheikhyoussef, A., Pogori, N., Chen, W., Zhang, H., 2008. Antimicrobial proteinaceous compounds obtained from bifidobacteria: from production to their application. Int. J. Food Microbiol. 125, 215-222.

Cheng, H., 2010. Volatile flavor compounds in yogurt: a review. Crit. Rev. Food Sci. Nutr. 50, 938-950.

Clark, S., 2009. The Sensory Evaluation of Dairy Products, second ed. Springer, New York.

De Angelis, M., Gobbetti, M., 2004. Environmental stress responses in Lactobacillus: a review. Proteomics 4, 106-122.

FAO/WHO, 2002. Guidelines for the Evaluation of Probiotics in Food: Report of a Joint FAO (Food and Agriculture Organization of the United Nations)/ WHO (World Health Organization) Working Group on Drafting Guidelines for the Evaluation of Probiotics in Food, vol. 2013. FAO, London Ontario, Canada.

Giraffa, G., 2012. Selection and design of lactic acid bacteria probiotic cultures. Eng. Life Sci. 12, 391-398.

Gueimonde, M., Delgado, S., Mayo, B., Ruas-Madiedo, P., Margolles, A., de los ReyesGavilán, C.G., 2004. Viability and diversity of probiotic Lactobacillus and Bifidobacterium populations included in commercial fermented milks. Food Res. Int. 37, 839-850.

Herrero, M., Simo, C., Garcia-Canas, V., Ibanez, E., Cifuentes, A., 2012. Foodomics: MS-based strategies in modern food science and nutrition. Mass Spectrom. Rev. 31, 49-69.

Hettinga, K.A., van Valenberg, H.J.F., Lam, T.J.G.M., van Hooijdonk, A.C.M., 2009. The origin of the volatile metabolites found in mastitis milk. Vet. Microbiol. 137, 384-387.

Lamanna, R., Braca, A., Di Paolo, E., Imparato, G., 2011. Identification of milk mixtures by $1 \mathrm{H}-\mathrm{NMR}$ profiling. Magn. Reson. Chem. 49, S22-S26.

Lourens-Hattingh, A., Viljoen, B.C., 2001. Yogurt as probiotic carrier food. Int. Dairy J. $11,1-17$

Lu, J., Antunes Fernandes, E., Paez Cano, A.E., Vinitwatanakhun, J., Boeren, S., van Hooijdonk, T., van Knegsel, A., Vervoort, J., Hettinga, K.A., 2013. Changes in milk proteome and metabolome associated with dry period length, energy balance, and lactation stage in postparturient dairy cows. J. Proteome Res. 12, $3288-3296$
Martinez, F.A.C., Balciunas, E.M., Converti, A., Cotter, P.D., de Souza Oliveira, R.P. 2013. Bacteriocin production by Bifidobacterium spp.: a review. Biotechnol. Adv. 31, 482-488.

Maus, J.E., Ingham, S.C., 2003. Employment of stressful conditions during culture production to enhance subsequent cold- and acid-tolerance of bifidobacteria. J. Appl. Microbiol. 95, 146-154.

Mills, S., Stanton, C., Fitzgerald, G.F., Ross, R.P., 2011. Enhancing the stress response of probiotics for a lifestyle from gut to product and back again. Microb. Cell. Fact. 10 (Suppl. 1), S19.

Mohammadi, R., Sohrabvandi, S., Mohammad-Mortazavian, A., 2012. The starter culture characteristics of probiotic microorganisms in fermented milks. Eng Life Sci. 12, 399-409.

Mozzetti, V., Grattepanche, F., Berger, B., Rezzonico, E., Arigoni, F., Lacroix, C., 2013. Fast screening of Bifidobacterium longum sublethal stress conditions in a novel two-stage continuous culture strategy. Benef. Microbes 4 $167-178$

Mozzi, F., Ortiz, M.E., Bleckwedel, J., De Vuyst, L., Pescuma, M., 2013. Metabolomics as a tool for the comprehensive understanding of fermented and functional foods with lactic acid bacteria. Food Res. Int. 54, 1152-1161.

Østlie, H.M., Helland, M.H., Narvhus, J.A., 2003. Growth and metabolism of selected strains of probiotic bacteria in milk. Int. J. Food Microbiol. 87, 17-27.

Park, S.J., Hyun, S.H., Suh, H.W., Lee, S.Y., Sung, G.H., Kim, S.H., Choi, H.K., 2013. Biochemical characterization of cultivated Cordyceps bassiana mycelia and fruiting bodies by $1 \mathrm{H}$-nuclear magnetic resonance spectroscopy. Metabolomics 9, 236-246.

Piras, C., Cesare Marincola, F., Savorani, F., Engelsen, S.B., Cosentino, S., Viale, S., Pisano, M.B., 2013. A NMR metabolomics study of the ripening process of the Fiore Sardo cheese produced with autochthonous adjunct cultures. Food Chem. 141, 2137-2147.

Reis, J.A., Paula, A.T., Casarotti, S.N., Penna, A.L.B., 2012. Lactic acid bacteria antimicrobial compounds: characteristics and applications. Food Eng. Rev. 4 124-140.

Rodrigues, D., Santos, C.H., Rocha-Santos, T.A.P., Gomes, A.M., Goodfellow, B.J. Freitas, A.C., 2011. Metabolic profiling of potential probiotic or synbiotic cheeses by nuclear magnetic resonance (NMR) spectroscopy. J. Agric. Food Chem. 59 4955-4961.

Ross, R.P., Desmond, C., Fitzgerald, G.F., Stanton, C., 2005. Overcoming the technological hurdles in the development of probiotic foods. J. Appl. Microbiol. 98 1410-1417.

Ruiz, L., Ruas-Madiedo, P., Gueimonde, M., De Los Reyes-Gavilán, C.G., Margolles, A. Sánchez, B., 2011. How do bifidobacteria counteract environmental challenges? mechanisms involved and physiological consequences. Genes. Nutr. 6 307-318.

Saarela, M., Rantala, M., Hallamaa, K., Nohynek, L., Virkajärvi, I., Mättö, J., 2004 Stationary-phase acid and heat treatments for improvement of the viability of probiotic lactobacilli and bifidobacteria. J. Appl. Microbiol. 96 1205-1214.

Saleh, F.A., El-Sayed, E.M., 2004. Isolation and characterization of bacteriocins produced by Bifidobacterium lactis BB-12 and Bifidobacterium longum BB-46. In: 9th Egyptian Conference for Dairy Science and Technology, Cairo, pp. 323-337.

Sánchez, B., Champomier-Vergès, M.C., Collado, M.D.C., Anglade, P., Baraige, F. Sanz, Y., De Los Reyes-Gavilán, C.G., Zagorec, A.M.M., 2007. Low-pH adaptation and the acid tolerance response of Bifidobacterium longum biotype longum. Appl. Environ. Microbiol. 73, 6450-6459.

Sánchez, B., Ruiz, L., Gueimonde, M., Ruas-Madiedo, P., Margolles, A., 2012. Toward improving technological and functional properties of probiotics in foods. Trends Food Sci. Technol. 26, 56-63.

Sánchez, B., Ruiz, L., Gueimonde, M., Margolles, A., 2013. Omics for the study of probiotic microorganisms. Food Res. Int. 54, 1061-1071.

Serrazanetti, D.I., Guerzoni, M.E., Corsetti, A., Vogel, R., 2009. Metabolic impact and potential exploitation of the stress reactions in lactobacilli. Food Microbiol. 26, 700-711.

Settachaimongkon, S., Nout, M.J.R., Antunes Fernandes, E.C., Hettinga, K.A. Vervoort, J.M., van Hooijdonk, T.C.M., Zwietering, M.H., Smid, E.J., van Valenberg, H.J.F., 2014a. Influence of different proteolytic strains of Streptococcus thermophilus in co-culture with Lactobacillus delbrueckii subsp. bulgaricus on the metabolite profile of set-yoghurt. Int. J. Food Microbiol. 177, 29-36.

Settachaimongkon, S., Nout, M.J.R., Antunes Fernandes, E.C., van Hooijdonk, A.C.M., Zwietering, M.H., Smid, E.J., van Valenberg, H.J.F., 2014b. The impact of selected strains of probiotic bacteria on metabolite formation in set-yoghurt. Int. Dairy J. $38,1-10$

Shah, N.P., 2000. Probiotic bacteria: selective enumeration and survival in dairy foods. J. Dairy Sci. 83, 894-907.

Shiby, V.K. Mishra, H.N., 2013. Fermented milks and milk products as functional foods: a review. Crit. Rev. Food Sci. Nutr. 53, 482-496.

Tamime, A.Y., Robinson, R.K., 2007. Tamime and Robinson's Yoghurt: Science and Technology, third ed. CRC Press, Cambridge.

Tsakalidou, E., Papadimitriou, K., 2011. Stress Responses of Lactic Acid Bacteria. Springer, New York.

Upadrasta, A., Stanton, C., Hill, C., Fitzgerald, G., Ross, R.P., 2011. Improving the stress tolerance of probiotic cultures: recent trends and future directions. In: Tsakalidou, E., Papadimitriou, K. (Eds.), Stress Responses of Lactic Acid Bacteria. Springer, New York, pp. 395-438. 
Urbach, G., 1995. Contribution of lactic acid bacteria to flavour compound formation in dairy products. Int. Dairy J. 5, 877-903.

Van de Guchte, M., Serror, P., Chervaux, C., Smokvina, T., Ehrlich, S., Maguin, E. 2002. Stress responses in lactic acid bacteria. Ant. Van Leeuwenhoek 82, 187-216.
Vasiljevic, T., Shah, N.P., 2008. Probiotics: from Metchnikoff to bioactives. Int. Dairy J. $18,714-728$.

Waddington, L., Cyr, T., Hefford, M., Hansen, L.T., Kalmokoff, M., 2010. Understanding the acid tolerance response of bifidobacteria. J. Appl. Microbiol. 108, 1408-1420. 